\title{
A TRANSGRESSÃo MODERNA E PÓS-UTÓPICA DE ULISSES
}

\author{
por Carolina Dônega Bernardes ${ }^{1}$
}

\begin{abstract}
RESUMO: Largamente retomado pela tradição literária, o tema da viagem de Ulisses em muitas de suas representações confirma o ideal do herói nostálgico que se dirige ao lar em cumprimento de seu nóstos, assim como, em outras, reafirma o ímpeto do eterno navegador de mares. Diversas são as representações da última viagem de Odisseu, entre elas a Divina Comédia de Dante, Ulisses de Joyce, Odisséia de Nikos Kazantzakis e Finismundo de Haroldo de Campos. Pretendemos, neste artigo, avaliar a retomada do mito homérico por Kazantzakis no contexto da modernidade e Haroldo de Campos na pós-modernidade.

Palavras-Chave: Ulisses, Nikos Kazantzakis, modernidade, Haroldo de Campos, pós-modernidade, transgressão.
\end{abstract}

ABSTRACT: Always invoked by the literary tradition, the travel of Ulysses confirms, in some works, the ideal of the nostalgic hero bounded for home in order to achieve his nóstos, and, in other works, it reaffirms the impetus of the eternal sailor. Several are the representations of the last journey of Odyssey, including the Divine Comedy by Dante, Ulysses by Joyce and Odyssey by Nikos Kazantzakis. We intend in this article, to evaluate resumption of Homeric myth by Kazantzakis in the context of modernity and Haroldo de Campos in postmodernity.

KEYWORDS: Ulysses, Nikos Kazantzakis, modernity, Haroldo de Campos, post-modernity, transgression.

\section{A Última Viagem}

A figura de Odisseu constitui, desde o início de sua existência mítico-literária, um modelo, uma forma "multiforme" (polytropos) de vida humana cheia de potencialidades. As múltiplas características do herói lendário provêm das diversas tradições clássicas que procuraram traçar seus passos, desde o nascimento até seu retorno à pátria, e de diversas interpretações de sua simbologia por filósofos e escritores. Inúmeras vezes representado na tradição literária por escritores como Dante, Shakespeare, Giovanni Pascoli, Gabriele d'Annunzio, Alfred Tennyson, James Joyce, Haroldo de Campos, Nikos Kazantzákis, entre outros, Odisseu é uma figura que não se esgota e não se limita aos poemas homéricos, sendo definido, genericamente, pela crítica contemporânea como um "discurso" da civilização ocidental.(BOITANI, 2005, p. XIV)

O legado de Ulisses que parece ter suscitado maior abertura para especulações e tentativas de compreensão do mito se instala na própria Odisséia de Homero, com a previsão do adivinho Tirésias, quando o herói faz sua descensão ao Hades, no canto XI. Como é comum nas previsões de adivinhos e oráculos, a mensagem de Tirésias prolonga-se ao futuro por sua ambiguidade, marcada na expressão grega thanatos ex halos, que pode significar que o herói teria uma morte "vinda do mar" ou "distante do mar". Piero Boitani (2005), em A Sombra de Ulisses, concentra-se a deslindar os desdobramentos que a expressão ambígua teria

\footnotetext{
${ }^{1}$ Doutoranda em Teoria da Literatura pela UNESP (campus São José do Rio Preto), bolsista FAPESP.
} 
suscitado na tradição literária, defendendo que a permanência do tema de Ulisses na literatura e na cultura ocidental se justifica por essa abertura deixada na fala de Tirésias.

Segundo a previsão do conhecido adivinho, após o seu retorno à Ítaca, Odisseu deveria enfrentar "uma enorme prova, longa e difícil", embarcando para uma última viagem, e levando consigo, nos ombros, um remo; deveria, em seguida, prosseguir seu trajeto até chegar a um país cujos habitantes não conhecem nem a comida temperada com sal, nem o mar, nem os remos, "que são para as naus as asas" (HOMERO, v.125). Ele reconhecerá o local por um "sinal muito claro", porque aí outro viajante, encontrando com ele, confundiria seu remo com um ventilabro, isto é, uma larga pá de madeira usada para espalhar as sementes (de trigo) ao vento. Então Odisseu deveria praticar sacrifícios apropriados para aplacar definitivamente a ira de Poseidon; só então a morte chegaria ex halos "tão serenamente que o encontrará consumido por esplendorosa velhice". (HOMERO, v. 134-136)

A profecia, no entanto, não se concretiza em Homero, permitindo, assim, que os leitores da obra completem a seu modo as várias possibilidades assinaladas pelo vate sentenciador também do destino do rei Édipo. Por essa previsão, Odisseu torna-se uma figura de longa duração, aberta às diversas interpretações, que intentam completar o anúncio de Tirésias. Assim, além de revelar a morte do herói pela expressão ambígua, o adivinho abre mais uma possibilidade para o futuro: sua viagem não terminaria com a chegada a Ítaca, como ocorre em Homero, mas se prolongaria para além do nóstos. Desse modo, Odisseu torna-se o viajante por excelência, ininterruptamente.

A partir desse momento, e cada vez que empreende aquela viagem, ele é signo. Cada cultura está livre para interpretá-lo como tal no âmbito de seu próprio sistema de signos, atribuindo-lhe uma dupla valência, ora baseada nas características míticas do personagem, ora nos ideais, nas questões, nos horizontes filosóficos, éticos e políticos daquela civilização. Histórica e múltipla torna-se sua representação, recebendo significados diversos em cada cultura.

Dessa forma, se para Homero Odisseu é o paradigma do conhecimento do mundo e de si mesmo na dor, para o império romano é o ícone da experiência, da ciência e da sabedoria; mestre de retórica, engano, ilusão e domínio, para Sófocles e Shakespeare, trazendo fundidas todas essas características em Dante.

Mas se a primeira viagem do herói foi marcada pelo destino certeiro, o retorno ao lar, a última viagem de Odisseu não tem meta precisa, ao contrário, segue em direção à morte, ao nada, ao não-ser. $\mathrm{O}$ famoso e lendário herói perde seu nome nesta viagem derradeira, pois a predição já estabelece que seu fim está no thanatos ex halos.

A frequência com que o mito do Ulisses $^{2}$ insatisfeito aparece na literatura do final do século XIX e com maior complexidade no século XX, nas obras de James Joyce, Kazantzakis e Haroldo de Campos, possivelmente seja o reflexo do espírito deserdado dessa época, que volta continuamente ao mito antigo, para procurar os fundamentos da história e da poesia, quase se agarrando a ele como a intermediação entre o todo e o nada. (BOITANI, 2005, p.100)

Tal tradição tem como principal raiz a Divina Comédia, lembrando que Ulisses aparece no canto XXVI do Inferno, relatando aos dois poetas (Dante e Virgílio) o final de sua vida, que não ocorrera entre os limites de Ítaca, mas que lhe sobreviera a morte do mar salino em adiantada velhice, após novas peripécias. Assim como toda a trajetória mística da Divina Comédia, o relato desse novo Ulisses, que concretiza o conhecido vaticínio, permanece fortemente arraigado na tradição literária e cultural que sucede a obra, promovendo uma torrente de produções inspiradas direta ou indiretamente no poema medieval.

\footnotetext{
${ }^{2}$ É preciso notar que preferimos a utilização do nome grego Odisseu, mas não se pode desconsiderar a utilização latina Ulisses, amplamente aceita pela tradição, justificando-se a alternância dos nomes que se referem à mesma figura.
} 


\section{DO NÓSTOS À MARCHA: MODERNIDADE DE ODISSEU}

Herdeiro indireto de Dante (e direto de Homero), o autor grego Nikos Kazantzakis (1883-1957) compõe na modernidade nova Odisséia (1938), poema épico de dimensões admiráveis - 33.333 versos de 17 sílabas poéticas, em 24 cantos -, no qual retoma o tema de Ulisses, tomando início no canto XXII, verso 477, da Odisséia de Homero, quando o herói acabara de exterminar os pretendentes de Penélope. A continuação dos feitos do herói lendário, entretanto, reorienta o sentido do destino glorioso do herói clássico. Logo em seu primeiro encontro com a esposa, o filho e o pai, longe de sentir-se apaziguado pelo fim das atribulações do trajeto de retorno ao lar, o Ulisses kazantzakiano sente um profundo desencanto, e sua ilha tão desejada torna-se a seus olhos estreita e asfixiante. Decide, então, partir novamente, com alguns poucos companheiros, sem rumo determinado. Se na primeira Odisséia o tema é a volta (nóstos), na Odisséia kazantzakiana há uma tentativa clara de superação da meta representada pela chegada à Ítaca. Como reavaliação moderna do herói de Homero, o herói de Kazantzakis mantém-se em marcha, ultrapassando suas próprias conquistas, visto que a chegada não manifesta nele o apaziguamento, e sim o desejo de ir além. Nesta nova representação, Ulisses descobre que a "superação" é constituída pelo próprio caminho, e então, lança-se novamente à viagem.

Homem de múltiplos conhecimentos, experiente e sábio, o Odisseu de Kazantzákis não se contenta com os valores tradicionais e estabelecidos, deseja a fruição completa da vida. Tal sede de conhecimento e de experiências não é, porém, hedonística ou de mero aproveitamento da vida em sua plenitude, mas liga-se à ideia de prolongar as ações dos antepassados, de modo que não sejam esquecidos e não se dissolvam no mundo dos mortos e sim que sirvam de adubo, de impulso para que o descendente siga mais longe, superando-se e promovendo a fundação do super-homem.

A superação, representada aqui pelo eterno viajar, associa-se ao pensamento de Nietzsche, filósofo que, por meio de Zaratustra, incentiva a força nos homens, sem qualquer intervenção divina. Em comunhão com as ideias de Nietzsche, e ainda com as de Bergson e da religião budista, Kazantzákis compõe seu próprio itinerário de superação e a ele nomeia ascese. Antes mesmo de encontrar em Ulisses seu protótipo de herói e de oferecer-lhe uma nova jornada a partir do retorno à Ítaca, o autor já elaborara em Ascese Os salvadores de Deus (1927) as etapas de elevação para o alcance da liberdade plena.

Para Kazantzákis, a ascese não é a simples elevação ao sagrado por meio de mortificações ao corpo praticadas por ascetas e religiosos, mas é um percurso de superação de valores, dogmas e conceitos, formadores do pensamento e atitudes do homem, que o impedem de realizar avaliações próprias da realidade e ceifam seu poder criador. Assim, o autor não adota um único caminho para compor sua visão de mundo, mas aponta em várias direções como possibilidades para as escolhas criadoras do homem. A ascese kazantzakiana indica que o entendimento apurado e mais próximo da completude de um determinado conceito ou valor só poderá ser alcançado com o apoio de diversas formas de pensamento, com a abertura das perspectivas, com a variação dos prismas.

Coadunado com o pensamento de Nietzsche, Kazantzákis expressa sua desconfiança pelos valores que inibem o potencial criativo do homem, considerados como "niilistas". Para combater esse niilismo negativo e restituir ao homem o direito à criação, Nietzsche elabora uma estratégia igualmente "niilista", mas ativa: inverter e superar a oposição de valores criada pelo platonismo e pelo cristianismo, afirmar que o mundo sensível é o mundo verdadeiro e o supra-sensível o mundo aparente, rebelar-se contra a dicotomia de dois mundos e a oposição metafísica entre a verdade e a aparência. O mais importante dessa estratégia de transvaloração 
não é apenas a quebra dos valores niilistas, mas a autonomia de criação de novos valores fundamentados no pulsar próprio da vida.

A fim de restituir ao homem esse potencial criativo e de transformação, Kazantzákis interioriza o niilismo nietzscheano, particularizando o escopo de sua atuação, transformando a afirmação dionisíaca do crescimento em meio ao declínio em uma aceitação total da vida. Com isso, propõe, segundo José Paulo Paes (1985, p.160), um "niilismo heróico" que leva as personagens kazantzakianas ao enfrentamento do perigo. $\mathrm{O}$ niilismo heróico é, pois, a recusa dos valores arraigados na tradição metafísica (individualidade, subjetividade, racionalidade, divindade salvadora, recompensa ao final da luta), contemporânea da aceitação heróica, dionisíaca, de participar da vida em sua plenitude, nas suas alegrias e nas duas dores.

Pelo niilismo heróico compreende-se a ânsia de Odisseu em manter-se em marcha, não permitindo que seu espírito se encerre nos estreitos limites fundadores de Ítaca, mas rompendo inicialmente com a família e a pátria para galgar novos degraus de sua elevação rumo à liberdade, que coincide plenamente com o poder criador do homem.

Se a unidade familiar já não existe, a meta do retorno perde seu significado e a permanência em Ítaca não tem qualquer sentido. Assim, o herói kazantzakiano move-se em direção centrífuga, para longe do centro fixado por Homero, assumindo a trajetória de se despojar de crenças em deuses olímpicos (ou no Deus cristão) e de valores do mundo clássico e também do mundo moderno. Não é, portanto, um distanciamento das tradições homéricas, já que o herói se afasta (ou supera) igualmente de quaisquer valores ocidentais, mas uma reavaliação criativa dos elementos formadores do pensamento ocidental, inaugurado por Homero. É preciso deixar claro que Kazantzakis não propõe a oposição desafiadora e niilista ao passado clássico, nem tampouco às representações mais recentes da Idade Moderna, mas combina os mais diversos sistemas de significação, aproveitando informações tanto da Grécia homérica, como das tradições sucessoras; combinados esses elementos e associados ainda à postura de superação (niilismo heróico), Kazantzakis traça para Odisseu o itinerário que desautoriza discursos sedimentados por meio da incorporação de certos valores, a saciedade pelo excesso e a ruptura, em direção à livre avaliação e criação da vida. "Odisseu transcende as contradições porque ele agora vê as oposições em um amplo e positivo contexto que as inclui e as integra”. (BIEN, 2007, p.210)

A crise da modernidade, consubstanciada pelo infindável paradoxo de que os artistas foram fundadores e vítimas a um só tempo, responde à natureza igualmente paradoxal da captação temporal. Se por um lado os conceitos e definições de modernidade são fugidios e inapreensíveis em sua totalidade, a autoconsciência de crise parece despertar para o que há de imutável no passado, reforçando indefinidamente o jogo que se lança ao passado mais remoto para reoperá-lo no presente. Estaríamos diante, portanto, da clara conformidade entre a técnica do mosaico, que cola os estilhaços do tempo na tela branca do panorama presente, e o momento histórico da amplitude de escolhas, todas elas entrelaçadas num imenso calidoscópio. É pela intertextualidade que a modernidade se volta ao passado milenar e não ao imediato, com o qual rompe, em busca da "outra metade" da arte, circunscrita ao eterno e imutável, para responder ao que é transitório, contingente, fugitivo.

As linhas da modernidade inscritas sobre o texto da antiguidade refletem um movimento recorrente das primeiras décadas do século XX de aproveitamento do mito como um recurso fecundo para impor ordem, poética ou simbólica, ao caos dos fatos cotidianos e oferecer a oportunidade de interromper a lógica do cientificismo moderno (McFARLANE, 189, p.64). Obedecendo às sugestões subjetivas e à irracionalidade do inconsciente, o mito oferecia uma nova percepção das realidades inconstantes, "uma maneira de controlar, ordenar, dar forma e sentido ao imenso paradoxo de futilidade e anarquia que é a história contemporânea”. (ELIOT apud MORETTI, 2007, p.225) 
Não é um olhar de museu que a modernidade dirige aos mitos, aquele olhar passadista, que procura captar nos monumentos e tesouros inanimados a essência de certa existência, acabada e para sempre silenciada; evidencia-se, ao contrário, por um movimento dinâmico de perpétua recolocação em questão de ideias e teorias ininterruptas. A eterna juventude dos mitos, sempre reavivada pela memória - ainda que algumas épocas literárias tenham procurado mantê-los no esquecimento ${ }^{3}$ - alcança a modernidade como potencial para a criação do novo.

A prática do palimpsesto tornou-se a técnica de escritores como T. S. Eliot, poeta consciente de que o impulso de escrever nasce de uma experiência literária prévia, preexistente a qualquer poema que se vanglorie como "novo"; nas expressões consideradas novas se encontram as forças matriciais de antigas culturas literárias e filosóficas. Esse traço de união estabelecido tacitamente entre as realizações literárias presentes e passadas foi reconhecido por Eliot que, além de explorar em seus poemas "um método complexo de entremear cadências poéticas antigas e modernas" (BRADBURY, 1989, p. 159), desenvolveu uma crítica sobre a poética moderna em seus ensaios. Em estudo sobre Eliot, Northrop Frye (1998) analisa o pensamento ensaístico do poeta, para quem a originalidade na literatura não pode ser alcançada plenamente, pois "cada poeta herda um continuum literário que vem desde Homero e sente que esse continuum 'tem uma existência simultânea e compõe uma ordem simultânea'. Sua relação com a tradição literária pode ser implícita ou explícita”. (FRYE, 1998, p.33)

Em sua produção poética, Eliot estabelece o vínculo com a tradição e ao mesmo tempo se separa dela, ao recorrer aos recursos da paródia, do pastiche, das citações e alusões. Tais recursos, utilizados e dispostos de maneira fragmentária, procuravam nesta inter-relação mostrar a unidade temporal e ainda o declínio da história. Relacionando a sensibilidade mítica e religiosa com o mundano, Eliot revelava, assim como Joyce em Ulisses, "a consciência do colapso dos mitos e rituais tradicionais, juntamente com o desejo de reconstruí-los". (BRADBURY, 1989, p. 171)

Também por meio da paródia, Joyce zomba da forma épica e a reconstrói ao afirmar um novo tipo de heroísmo, muito distante da conformação homérica, o heroísmo do homem comum, que nada empreende de fabuloso, mas que procura sentido no mundo moderno das trivialidades. No mundo de Ulisses, não há mitos, todos foram reduzidos e relegados ao passado, mas as coisas corriqueiras e aparentemente ínfimas do cotidiano ganham uma função mítica. Desse modo, é possível afirmar que Joyce se utiliza do mito para dessacralizá-lo e assim dessacralizar a sua época.

O mito de Ulisses oferece a Joyce a representação simbólica da vida humana de maneira atemporal, figura original correlata ao homem comum dos tempos modernos, que evoca, já no passado, os temas mais atuais: o exílio e a errância, o anseio de reintegração após a perda do lar, a necessidade de reencontro erótico (homem-mulher) e filial (pai-filho). Joyce utiliza-se de Ulisses pela "necessidade", já que vê no antigo herói "o primeiro personagem simbólico da era cultural da qual Joyce é o último produto". (MORETTI, 2007, p. 227) O paralelo central que o autor estabelece entre Ulisses e Bloom pode ser definido pela justaposição irônica de um herói elevado, honrado e famoso com o anti-herói burguês, fruto de uma época de incertezas e de esterilidade espiritual.

O paralelismo com Homero mantém-se por toda a obra, sustentando o caráter aproximativo e geral, ou seja, Joyce não busca na Odisséia particularidades específicas dos personagens, nem tampouco da mitologia grega, mas serve-se da configuração genérica para expressar a repetição universal de comportamentos e situações modelares. As alusões

\footnotetext{
${ }^{3}$ Como o Realismo, "que se orientava conscientemente na representação verossímil da realidade, na criação da história artística do seu tempo e só implicitamente admitia elementos de mitologismo". (MIELIETINSKI, 1987, p. 2)
} 
constantes à obra de Homero se revelam pela paródia, o canto instaurado paralelamente ao original que serve de imitação e zombaria. O recurso da paródia - neste caso, mitológica - é a plena afirmação de que escrever é sempre reescrever, num processo duplo que leva da revisão da escritura para a visão do novo.

Pela análise do período literário da modernidade compreende-se que a ideia de continuidade de determinada tradição (ou de uma multiplicidade delas) se faz pela aproximação temática ou mitológica, seja no intuito de nutrir-se do antigo para reavaliação do atual, seja para a criação de uma nova espécie de mitologia.

A Odisséia de Kazantzakis reflete, assim, a busca universal do homem por um abrigo depois da "morte de Deus", no espaço do não-ser, do nada, em trágica angústia pela necessidade de criar "ilhas de lucidez em meio a um oceano de confusões e ao desmoronamento de todos os mitos". (KARALÍS, 1994, p. 200). Deste modo, como "hino à frágil grandeza do homem" (DECAUX, 1968, p. 10), a Odisséia de Kazantzakis trata de conter todos os caminhos e visões, acumulando mitos, lendas, costumes, cantos populares, crenças de diversos povos e épocas (PIZARRO, 2003, p. 311), surgindo Ulisses como atravessador das angústias e esperanças contemporâneas. São derrubadas as cidades, os reinos, as falsas crenças, todos os deuses; a morte é a última realidade. "O poeta contempla, pois, com Ulisses, a lenta e completa destruição dos valores sobre os quais se havia apoiado a sociedade". (BIDAL-BAUDIER, 1986, p. 181). A ruptura com todos os valores, entre eles a própria esperança, se revela na passagem em que Odisseu recebe de Hércules a última tarefa:

\author{
O matador-de-deuses se inclina mais para escutar, mas o mugido cessara; \\ Pendeu suas mãos até a terra e clama na escuridão: \\ "Lança, ancião, a última tarefa sobre minha cabeça!" \\ E da outra margem se ouviu a terrível garganta: \\ "Quando tua entranha se esvaziar de deuses e demônios, \\ de virtudes magnas e pequenas, de alegrias e amarguras, \\ e fique o espírito apenas, esta luz de Caronte, \\ levanta-te, herdeiro, e inclemente, repartas em dois teu espírito: \\ Abaixo, o último inimigo, e o mais forte, a impudica Esperança, \\ E acima, a chama indomável, sem fogo nem ar nem luz, \\ Sobre-humana, desdenhosa, sobre o sacro crânio desesperançado!"
}

(KAZANTZAKIS, 1975, XVI, 1174-1183)

\title{
3. TransGRESSÃo E TRANSCRIAÇÃO DE ODISSEU
}

Mas se o destino de Ulisses não se circunscreve aos limites da Ítaca homérica e se espraia para novas dimensões de espaço e tempo, é importante avançar para além da modernidade, recuperando, todavia, a abertura franqueada por Dante e pelo relato de Ulisses acerca de seu destino para além do nóstos. Interessa-nos no momento outro aspecto encontrado na obra de Dante, que servirá igualmente para a compreensão das obras do século XX que ousaram explorar, por seu turno, a figura de Ulisses associada à expressão thanatos ex halos.

Interessa-nos, então, a expressão folle volo, que pode ser traduzida como "vôo tresloucado".4. A última viagem de Odisseu concentra-se na hybris, a desmedida, a ultrapassagem dos limites estabelecidos. É com a desmesura intentada pelo herói, e com ele

\footnotetext{
${ }^{4}$ Referência aos remos que "são para as naus as asas".
} 
todos os homens, que Haroldo de Campos inicia seu poema Finismundo (1990), com a epígrafe italiana "...per voler veder trapassò il segno", (CAMPOS, 1990, p. 39), atribuída a Boccaccio, que a utilizou para descrever a empresa do Ulisses de Dante (BOITANI, 2005, p.159). A expressão não aparece no poema italiano como se encontra em Finismundo, mas as mesmas palavras trapasso e segno, com sua carga semântica, surgem esparsas no canto XXVI. Ao se referir ao estreito de Gibraltar, miticamente conhecido como "as colunas de Hércules", o Ulisses de Dante o nomeia "grande passo" (DANTE, XXVI, v. 132), raiz de trapasso; ainda no canto referido do Inferno, é dito que Hércules colocou os seus segno (limites) em Gibraltar (DANTE, XXVI, v. 108), a fim de que o homem não os ultrapassasse. $\mathrm{O}$ vôo tresloucado de Dante (il folle volo) igualmente confirma que o motivo do poema de Haroldo de Campos é de fato a transgressão dos limites, estando presente na metade da primeira seção de Finismundo.

O poema de Haroldo de Campos, antes de qualquer consideração mais aprofundada a seu respeito, é parte de um intertexto quase global que evoca a hybris dantesca, na primeira parte do poema, e o homem comum de James Joyce, na segunda parte, o que obriga o leitor a continuamente realizar deslocamentos no tempo e na tradição. Assim, como o próprio poeta alude no prefácio à edição de Finismundo, uma espécie de gênese do poema, há nele o confronto entre duas dicções. (CAMPOS, 1997, p.18)

A primeira seção é marcada por repetição de palavras em todas as catorze estrofes e por peculiar disposição imagética dos versos, que ora separa ora reúne as palavras, sugerindo, toda essa construção, o vaivém, ou marulho, do mar. Assim como em outros poemas seus e até mesmo em suas traduções, em Finismundo é nítida a potencialização da etimologia das palavras.

Profundamente conhecedor dos temas helênicos, Haroldo de Campos continuamente se volta ao mito de Ulisses e à forma épica, bem como se ancora na inspiração marítima para a composição de seus poemas. A tradição da última viagem de Odisseu retorna, pois, em Haroldo, marcada repetidamente pelo vocábulo "passo" (passar, trans-passar o passo: o impasse), em diálogo com a Comédia de Dante e pelas diversas referências ao mito da insaciabilidade, que faria Ulisses ousar o mais (CAMPOS, 1990, v. 25) e desejar o após: imprevisto filame na teia de Penélope (v. 26-27). Haroldo apresenta o último Odisseu multiardiloso (v. 1-3), seguidor, na contemporaneidade, de uma extensa cadeia de Odisseus. E assim como seus predecessores, o herói de Haroldo re-propõe a viagem (v. 4-5) para tentar o não tentando (v. 36), até onde se esconde a proibida geografia do Éden - Paradiso (v. 4344), onde Hércules fundou suas colunas como limites.

Mas se Odisseu ousa ir além do permitido e transgride as sigilosas siglas do Não, Haroldo de Campos não estaria confirmando a tradição? Repropor a viagem com a ânsia de superar os estabelecidos limites não é o mesmo que concordar com Dante, com Tennyson e com a própria previsão de Tirésias? Conferir ao desmedido Ulisses o castigo da morte por desafiar os deuses não é o mesmo destino que lhe foi dado pelo cânone da última viagem? A esse respeito, devemos inicialmente analisar as palavras do próprio poeta:

Sátira do mundo onde as ideologias entraram em crise e, ao mesmo tempo, celebração da aventura incessante, sempre renovada, do conhecimento e da criação, imaginei Finismundo como um poema "pós-utópico", expressão que prefiro ao conceito já gasto e equívoco de "pós-moderno". Nele, a operação criadora é também uma operação tradutora. Contudo, ao contrário do ecletismo e da aceitação conformista do passado, como ornamento nostalgicamente inócuo, é o espírito crítico (resíduo inalienável da utopia em crise) o fator que preside à escolha dos topoi e dos estilemas da tradição.

\footnotetext{
5 "Por vontade de ver, transpassou os limites".
} 
Leva-se em conta, a cada vez, o lema poundiano: make it new (fazê-lo novo). Lema que, sob esse ângulo, coincide com a razão antropofágica de Oswald de Andrade: devorar: remastigar a herança cultural universal, para "nutrir o impulso": renovar. Reimaginar os dados do passado (a tradição no que ela tem de virtualmente ativo) e reoperá-los sob a espécie da diferença brasileira na instância vital e problemática do presente. (CAMPOS, 2002, p. 57, grifo nosso).

Procurando reimaginar os dados do passado, por meio da figura heróica ocidentalmente canonizada, Haroldo de Campos articula o desmedido Ulisses com o everyman de James Joyce, que surge na segunda seção do poema. Castigado pela ousadia, o Ulisses de Finismundo é inserido no meio urbano, tornando-se homem comum, sem a heroicidade que o caracterizara até então. Não obstante, essa interpretação do mito igualmente encontra suas raízes no passado clássico, mais especificamente no livro X da República de Platão (2005, p. 318-319), em que, após a morte, Ulisses renuncia às suas características de herói, à fama e ao próprio nome, para tornar-se um simples idiotes (indivíduo particular, homem privado). Em Platão, Ulisses já é potencialmente o everyman, o homem qualquer, o Leopold Bloom do futuro, o protótipo do antimito. De certo modo, o desconhecido de Platão liga-se ao ignoto viandante da previsão de Tirésias.

Desse modo, se Joyce lança mão da tradição platônica para reoperá-la em seu presente, como topos de configuração da modernidade, Haroldo de Campos segue, portanto, duas tradições na pós-modernidade (ou pós-utopia, como ele próprio prefere), estabelecendo um diálogo com duas fortes representações do homem, a homérica e a platônica, ambas revistas no medievalismo e na Era Moderna e ligadas intrinsecamente pela perda da fama (kléos). Ao discurso da pós-modernidade, entretanto, não basta a ousadia do herói contra os deuses, visão mais causadora de espanto para a cultura cristianizada da Divina Comédia ou mais aplaudida pelo espírito científico do século XIX. Não basta, ademais, a consciência do abandono pelos deuses e do caráter ínfimo da vida cotidiana, sem exigências que mereçam os feitos grandiosos do homem moderno, levando-o ao anonimato e à consumição na coletividade. A angústia da vida moderna encontra-se nessa perda do nome e da fama e, em contrapartida, na aporia da individualização característica dessa época; diferente da coletividade, o indivíduo moderno não se distingue dos demais em suas ações, são todas elas comuns, genéricas, opacas.

Mas o heroísmo é uma ideia por demais romântica e utópica para que seja vangloriada e cantada na modernidade, é preferível o conflito de manter-se desconhecido, e ainda assim único na multidão, ao resgate do imaginário épico. O que, de certo modo, é contradito por Joyce: Leopold Bloom é um homem comum, sem qualquer traço que o eleve em sua categoria, porém um dia seu tem a enormidade de uma epopéia e os eventos ocorridos têm o revestimento de grandes acontecimentos, ainda que superficialmente sejam parte da vida cotidiana e comum de todos os homens.

A crise de fragilidade dos ideais humanistas e a consciência do declínio histórico das culturas que permearam as primeiras décadas do século $\mathrm{XX}$, desencadeadas pelo fim da Primeira Guerra Mundial, podem ter sido problematizadas por meio do contraste entre o herói destituído de habilidades do presente e o herói multiardiloso do passado. A dissonância entre as duas realidades inseridas no mesmo contexto representa o modo de estabelecer o conflito de forças irreconciliáveis e de engendrar um espaço de embate entre elas.

Os ecos da desolação que atingiu os meios culturais se estendem ainda à época "pósutópica", pois se observa a necessidade de debate com o cânone e com o passado, mesmo que seja para reoperá-lo no presente, de releitura do homem urbano debilitado e, consequentemente, de análise crítica e irônica dessa orfandade que se abate sobre a 
individualidade moderna. A literatura mais recente volta-se ao modernismo como herdeira natural, mas despende-lhe um olhar, muitas vezes, derrisório em relação à problemática das forças díspares que se entrechocam no espaço do texto literário, como a zombar da atmosfera de crise que pairava no ar e se transubstanciava em escrita fragmentada e múltipla, em sua ânsia por apanhar o todo e o nada que caracterizava a vida e o mundo.

Mais do que perseguir a tradição da última viagem de Ulisses, Haroldo de Campos retoma o passado (em momentos diversificados) para avaliar o presente, e a época imediatamente anterior, num movimento inverso da sucessão histórica, inserindo os valores de sua época nos temas primitivos. Remetendo seu olhar ao antigo, o poeta, mais uma vez, se apropria do tema clássico, seguindo tradições muito específicas, mas não para repropor o já proposto e sim transcriar a própria última viagem e a figura de Ulisses, e ainda satirizar o momento de "crise", com o distanciamento temporal imprescindível para o olhar crítico sobre os predecessores.

Assim, Finismundo apresenta a seção inicial como o início do discurso da última viagem, que compõe uma tradição estabelecida e inaugurada canonicamente por Dante, sendo transcriada pelo poeta com o movimento conferido às palavras, a exploração etimológica e neologística das palavras, com toda sua capacidade de síntese e composição inspirada no grego, e a imagética do poético. Em seguida, avança temporalmente e franqueia os umbrais da modernidade, reavivando o mesmo discurso do mito ulisseano, porém já inócuo e refém de si mesmo, protagonizando a perda total de sentido de uma época.

O poema significa, pois, a proposição, o colocar em debate, de uma antiga discussão, que se inicia a partir das leituras de Homero e alcança a modernidade para ser reproposta como meio de problematização de questões caras à poética do período. Observa-se o deslindar da evolução literária e da representação do homem (e não do herói), utilizando-se Ulisses como seu magno protótipo, tendo sua origem fundada no sério heroísmo em contraposição ao poderio e soberbia dos deuses, que deságua na simples debilidade e incapacidade humana de ousar, ou mesmo desejar, o mais-de-si. Ao mesmo tempo em que respeita a aventura e o clássico como topoi e estilema, como impulso para a renovação do momento presente, a transcriação de Haroldo de Campos considera risível a reapropriação do mito pela modernidade e a própria condição do homem que, outrora, foi considerado detentor de atributos semi-divinos para se transformar no apático urbano em relação com seu cotidiano destituído de deuses. Rir da descrença na raça humana é o cumprimento pós-utópico da última transgressão do homem, sua falibilidade diante dos deuses.

Assim, a modo de arremate, cada vez que se revisita o tema de Ulisses, novos conceitos e configurações se acrescentam à sua figura, pois os valores das respectivas épocas de sua representação são natural e forçosamente inseridos no contexto primitivo, como avaliação e recriação perenes: aventura incessante do conhecimento e da criação.. $\mathbf{d}^{\mathbf{d}}$ 


\section{REFERÊNCIAS BIBLIOGRÁFICAS:}

ALIGHIERI, Dante. A Divina Comédia. Tradução Hernani Donato. São Paulo: Cultrix, 1997, p.331.

BERNARDES, Carolina D. "El ignoto viandante y el itinerario rumbo a la nada". Byzantion Nea Hellás, Santiago, n.26, 2007, p.173-191.

BIDAL-BAUDIER, Marie-Louise. Nikos Kazantzakis. Cómo el hombre se hace inmortal. Traducción Patricio Canto. Buenos Aires: Carlos Lohlé, 1986.

BIEN, Peter. Kazantzakis. Politcs of the Spirit. Volume 1. New Jersey: Princeton University Press, 2007, p.316.

BOITANI, Piero. A sombra de Ulisses. São Paulo: Perspectiva, 2005, p.226.

BRADBURY, M. O mundo moderno. Dez grandes escritores. São Paulo: Companhia das Letras, 1989.

BRADBURY, M. e McFARLANE, J. (org.) Modernismo. Guia Geral. São Paulo: Companhia das Letras, 1989.

CAMPOS, Haroldo. Sobre Finismundo: a última viagem. Rio de Janeiro: ed. Sete Letras, 1997, p.58.

. Depoimentos de Oficina. São Paulo: Unimarco, 2002.

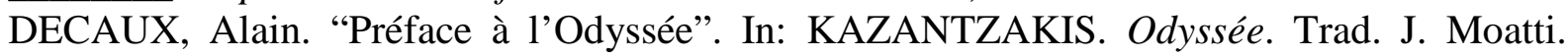
Paris: Ed. Plon, 1968.

FRYE, Northrop. T. S. Eliot. Rio de Janeiro: Imago, 1998, p.114.

HOMERO. Odisséia. Tradução: Carlos Alberto Nunes. Rio de Janeiro: Ediouro, 1967.

JOYCE, James. Ulisses. Tradução Antônio Houaiss. São Paulo: Abril Cultural, 1980, p.852.

KARALÍS, Vrasidas. «Sobre el nihilismo de la Odisea y del nihilismo en general ». In :

Nikos Kazantzakis y el palimpsesto de la historia. Atenas : Ed. Kanakis, 1994.

KAZANTZAKIS, Nikos. Odisea. Traducción de Miguel Castillo Didier. Barcelona: Planeta, 1975.

McFARLANE, J. "O Espírito do Modernismo". In: BRADBURY, M; McFARLANE, J. (org.). Modernismo. Guia Geral. São Paulo: Companhia das Letras, 1989.

MIELIETINSKI, E. M. A poética do mito. Trad. Paulo Bezerra. Rio de Janeiro: ForenseUniversitária, 1987, p.482.

MORETTI, Franco. "O longo adeus: Ulisses e o fim do capitalismo liberal". In: Signos e estilos da modernidade. Ensaios sobre a sociologia das formas literárias. Rio de Janeiro: Civilização Brasileira, 2007. p. 213-242.

PAES, J.P. "A última viagem de Ulisses". In: __ Gregos e Baianos. São Paulo: Ed. Brasiliense, 1985, p. 151-164.

PIZARRO, Roberto Quiroz. Nikos Kazantzakis. Dimensiones de un poeta-pensador. Santiago, Universidad de Chile, 2003, p.374.

PLATÃO. A República. São Paulo: Martin Claret, 2005.

VIZIOLI, Paulo. James Joyce e sua Obra Literária. São Paulo: EPU, 1991, p. 147. 